\title{
Efficiency of Solar Cells Employing Natural Dyes with Plasmonic Nano Particle Based Photo Anode
}

\author{
Kirti Sahu ${ }^{1}$, Mahesh Dhonde ${ }^{2}$, Khushboo Purohit ${ }^{1}$, V. V. S. Murty ${ }^{1}$ \\ ${ }^{1}$ Department of Physics, Govt. Holkar Science College, M.P., India \\ ${ }^{2}$ Department of Engineering Physics, Prestige Institute of Engineering Management and Research, M.P., India
}

Email address:

kirtisahu4star4@gmail.com (K. Sahu)

\section{To cite this article:}

Kirti Sahu, Mahesh Dhonde, Khushboo Purohit, V. V. S. Murty. Efficiency of Solar Cells Employing Natural Dyes with Plasmonic Nano Particle Based Photo Anode. Journal of Photonic Materials and Technology. Vol. 3, No. 1, 2017, pp. 1-5. doi: 10.11648/j.jmpt.20170301.11

Received: September 27, 2016; Accepted: October 12, 2016; Published: March 17, 2017

\begin{abstract}
Cheap and efficient dye sensitized solar cells (DSSCs) can be prepared using natural dyes responding in visible region of solar spectrum. Localized surface Plasmon resonance (LSPR) plays a very important role for the improvement in the efficiency of DSSCs by using Plasmonic nanoparticles (PNPs) for exploiting the visible portion of the solar radiation by transferring the energy from dye to PNP. This energy transfer from dye to low cost semiconductor $\mathrm{TiO}_{2}$ through PNP increases the overall photo catalytic activity. In the present study, natural and synthetic dyes are prepared and the optical transmittance and absorbance of the dyes are measured in the wavelength range of $250 \mathrm{~nm}$ to $850 \mathrm{~nm}$ using UV-Vis spectroscopy and they are used in DSSC. Natural dyes extracted from fruits and synthetic dye based on Ru metal complex is used as sensitizers. Photo Conversion Efficiency (PCE) of the solar cells utilizing different dyes are compared. Out of the various natural dyes, beetroot and strawberry extracts based dyes show good absorbance in the visible range of electromagnetic spectrum. On the other hand synthetic dye based on Ru complex shows strong absorbance over a wide range of visible spectrum. The absorbance increases with increase in concentration of $\mathrm{Ru}$ in ethanol. The extracts of beetroot, strawberry and mixed fruits show a peak in absorbance spectra at $501 \mathrm{~nm}, 416 \mathrm{~nm}$ and $332 \mathrm{~nm}$ respectively, indicating the absorption over wide range of visible spectrum. Maximum efficiency of solar cell obtained with synthetic and natural dyes are $5 \%$ and $1.5 \%$ respectively.
\end{abstract}

Keywords: Plasmonic Nano Particles, Transmittance, Absorbance, DSSC, Synthetic Dyes, Natural Dyes

\section{Introduction}

Dye sensitized solar cell (DSSC) was inspired by the energy and electron transfer mechanisms in natural photosynthesis. Natural dyes based solar cell is a low cost and eco-friendly concept to enhance efficiency of DSSC. DSSCs with PNPs are more efficient as compared to pure $\mathrm{TiO}_{2}$ based DSSCs $[1,2]$, due to their ability to scatter light back into the photovoltaic structure. Metal Nano Particles (NPs) are placed on top of the solar cell or incorporated inside the photoactive layer of the solar cell. The radiative decay of the LSP modes into propagating electromagnetic waves is observed as a scattering of incident light by the NPs. The scattering properties of large NPs (with diameter > $40 \mathrm{~nm}$ ) have often been used to increase the optical path length within solar cells and consequently to enhance the short-circuit photocurrent density.
When used with environmental friendly components for the energy generation, DSSCs are proven to be the best alternative energy source. But $\mathrm{TiO}_{2}$ based DSSC is not very efficient due to its large band gap corresponding to the absorption of sunlight limited to ultra violet region of solar spectrum. On the other hand solar cells based on Si possess low band gap hence Si based solar cells are more efficient due to their absorption of sunlight in both UV and visible region. Except the semiconductors like $\mathrm{TiO}_{2}$ or $\mathrm{Si}$, the efficiency/performance of solar cell depends on many components used in DSSC. One of the key materials to be considered in DSSCs is the sensitizer with suitable structural and physical properties capable of absorbing sunlight over a wide range of wavelengths. Both natural and synthetic sensitizers (dyes) have the property to absorb sunlight in a very wide region of solar spectrum. By choosing suitable dye, the incident photon to current efficiency (IPCE) of the $\mathrm{TiO}_{2}$ based DSSC can be improved in visible range. 
Out of various synthetic dyes, Ruthenium complex dyes are capable of sensitizing DSSCs with high conversion efficiencies [6]. However, $\mathrm{Ru}$ based complexes are very costly and hazardous to environment. Natural dyes are the alternate solution for the suitable sensitizer because its pigments are easily and safely extracted from plants and environmental friendly [8] with low cost, hence they are considered as one of the suitable option for dye sensitized solar cells in future research [10]. Natural dyes based DSSCs have low efficiency and demands parametric variation to increase the performance of the DSSC. The low cost DSSCs with high performance can be designed by using natural dyes.

The main limitations of using semiconductor photo catalysts, such as $\mathrm{TiO}_{2}$ and iron (III) oxide $\left(\mathrm{Fe}_{2} \mathrm{O}_{3}\right)$, for large scale applications have been the short range light response, poor light absorption rate, and high recombination rate of photo generated carriers, which result in low solar energy conversion efficiencies. By using suitable dye and metal Plasmonic nanoparticles (PNPs) onto conventional semiconductor photo catalysts e.g., $\mathrm{TiO}_{2}$, cadmium sulfide $(\mathrm{CdS})$, and $\mathrm{Fe}_{2} \mathrm{O}_{3}$, the incident photon to current conversion efficiency (IPCE) can be improved $[12,13,14,15,16,17,18,19,20,21,22,23$, $24,25,26,27,28]$.

\section{Mechanism of Dye Sensitized Solar Cells Based on PNP $_{S}$}

DSSC consists of two transparent conducting electrodes coated with pure $\mathrm{TiO}_{2}$ or metal doped $\mathrm{TiO}_{2}$ nanoparticles known as photo electrode and carbon or platinum coated electrode act as counter electrode, dye (sensitizer) which absorbs sunlight over a wide range of solar spectrum and electrolyte (redox couple) which regenerates dye and maintain continuity in the circuit.

The PNPs efficiently absorb visible light through localized surface Plasmon resonance (LSPR) and convert it into holes and electrons in the nearby semiconductors. Upon light irradiation, the electric field will displace the conduction electrons relative to the nuclei, inducing a large electric dipole. Simultaneously, a restoring force arises because of the Coulomb attraction between electrons and nuclei, which results in resonant oscillation of the conduction electrons at a certain frequency. This LSPR generally occurs when the PNPs are considerably smaller than the wavelength of the incident light. By increasing absorption cross section as compared to physical cross section, the LSPR of PNPs can lead to very efficient absorption of light which can enhance efficiency of DSSCs up to several times. LSPR induces electric dipoles which oscillate with the frequency of the incident photon which ultimately increases the intensity of the incident electric field $[11,29]$.

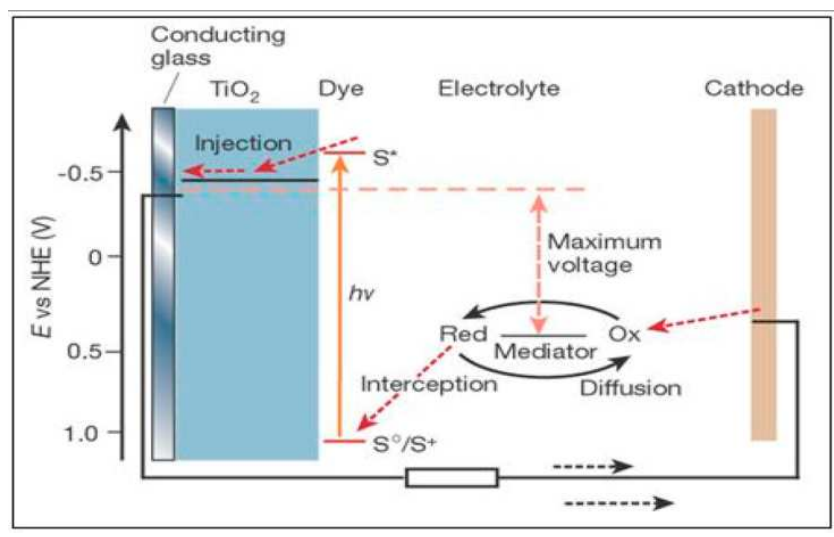

Figure 1. Schematic of mechanism of DSSC.

The mechanism of DSSC with different energy levels is shown in the figure. 1. Photons with different wavelengths incident on the photo anode of the cell and penetrate into the dye layer since both photo anode and the pure or doped $\mathrm{TiO} 2$ nano crystals are transparent to visible light. If the energy of the incident photon is close to the energy gap of the dye molecule, gets absorbed by the dye and promoting one electron from highest occupied molecular orbital (HOMO) to lowest unoccupied molecular orbital (LUMO)of the dye [30, 31]. The excited electron will then be injected into the conduction band of $\mathrm{TiO}_{2}$ through the interfacial bonds between the dye and the $\mathrm{TiO}_{2}$, and collected by the counter electrode. The hole which was generated by photon excitation remains on the molecule during the process since the HOMO of dye is separated from all other energy levels. The hole eventually will be filled up by electrons from electrolyte ions. At the same time, reduction of oxidized dye by iodide produces tri-iodide. The tri-iodide diffuses to a counter electrode and accepts electrons from external load, regenerating the iodides. The overall process will provide electron flow from the working electrode to the outer circuit $[32,33]$. The dye would be regenerated by the electrolyte solution and would get ready for the next photon [33].

\section{Materials and Methods of Dye Preparation}

\subsection{Preparation of Natural and Synthetic Dye as Sensitizer}

For natural dyes preparation, juice of various fruits have been extracted and mixed in a suitable amount of water for obtaining required concentration of the dyes. These freshly prepared extracts have been kept for 24 hours at room temperature and finally filtered for removing unwanted solid residue. Similarly synthetic dyes are prepared from the $\mathrm{Ru}$ based metal complex which is in the powder form (Solaronix, Switzerland) and mixed in the ethanol and filtered after keeping the dye over night at room temperature. These dyes are used as sensitizer for the adsorption onto the $\mathrm{TiO}_{2}$ nano particles and plasmonic metal nanoparticles. For keeping the dye solutions stable and usable for a long time, it is kept at low temperature and protected from direct exposure of light. 


\subsection{Preparation of Dye Sensitized Solar Cells}

For making photo anode of DSSCs, TCO with $1 \mathrm{~cm} \times 1 \mathrm{~cm}$ dimensions are cleaned by ultra sonicator and dried. Pure $\mathrm{TiO}_{2}$ and $\mathrm{Al}$ doped $\mathrm{TiO}_{2}$ paste with nanoparticles size ranging from 12 to $30 \mathrm{~nm}$ is coated on these TCO by using the doctor blade technique [34]. These coated TCO were sintered at $450^{\circ} \mathrm{C}$ for 30 minutes and then allowed to cool at room temperature. After cooling, the electrodes are immersed in the different dye solutions for a time period of 24 hours. These electrodes after adsorption of dye molecules on the layer of nanoparticles were rinsed thoroughly to remove the extra dye molecules. The dye adsorbed photo anode and carbon coated counter electrode were assembled in a sandwich type cell and then sealed using a thermoplastic sealing film made of Surlyn (Solaronix, witzerland). The Iodide/ triiodide electrolyte is injected in this sandwich assembly by using the hole provided at the counter electrode and sealed after injection.

\section{Results and Discussion}

\section{1. $U$ V-Vis Spectroscopy}

Ruthenium based dyes with different molar concentrations are prepared using ethanol as a solvent at room temperature. The samples are analyzed by using Perkin Elmer Lambda 950. This synthetic dye based on ruthenium complex with different concentrations has strong absorbance in the wavelength range of $450 \mathrm{~nm}$ to $700 \mathrm{~nm}$ giving possibility for enhanced efficiency of DSSCs.

The absorbance of the different concentration of the samples based on synthetic dyes and natural dyes is shown in the figure. 2 and figure. 3 respectively.

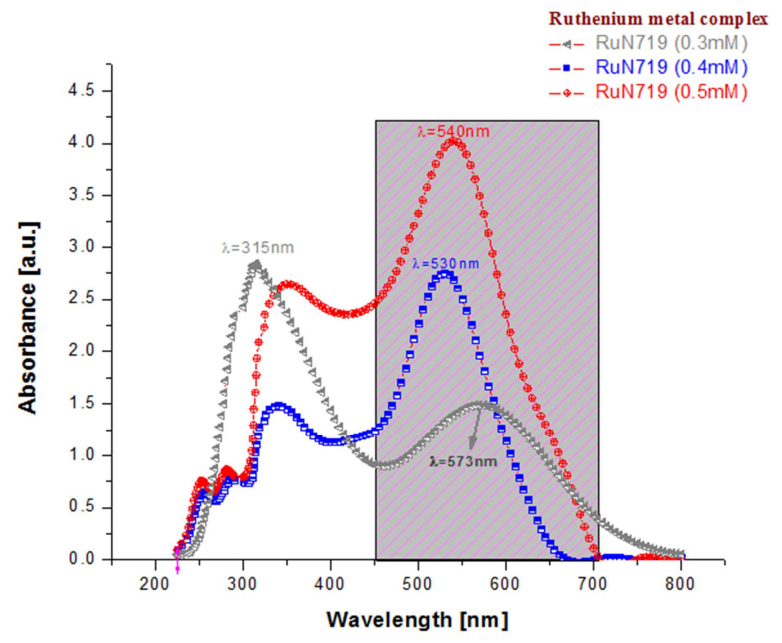

Figure 2. UV-Vis absorption spectra of synthetic dyes.

It is observed that the $\mathrm{Ru} 719$ with $0.5 \mathrm{mM}$ has a absorbance peak at $540 \mathrm{~nm}$ with absorbance 4.0A.U. Similarly for $0.4 \mathrm{mM}$ and $0.3 \mathrm{mM}$ have their absorbance peaks at $530 \mathrm{~nm}$ and $573 \mathrm{nM}$ and with absorbance of 2.7 and 1.5 A.U. respectively.
Similarly, UV-Vis spectra of natural dyes have shown absorption towards the wavelength range of $330 \mathrm{~nm}$ to $600 \mathrm{~nm}$.

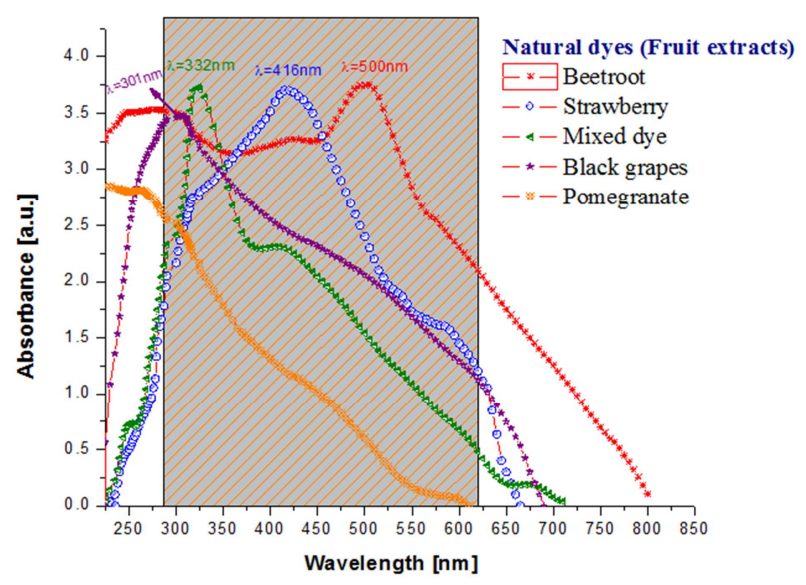

Figure 3. UV-Vis absorption spectra of natural dyes.

It is observed that the strawberry and beetroot have absorbance peaks at $416 \mathrm{~nm}$ and $500 \mathrm{~nm}$ with 3.7 and 3.8A.U. respectively. These results show that the natural dye is an alternate efficient candidate for photovoltaic performance of DSSCs at low cost. Extracts of beetroot and strawberry of extracts show absorption towards visible spectrum. These dyes are prepared by mixing fruit extracts in suitable amount of deionized water with constant stirring for 30 minutes. Even natural dyes have absorption towards higher wavelength range, the efficiency obtained with beetroot and strawberry is not suitable at large scale production because these dyes are not very stable. But the results are quite hopeful and by improving the experimental parameters, the efficiency of natural dyes based DSSC can be enhanced.

The photo response of both natural and synthetic dyes in the visible region for their absorbance is measured by UVVisible spectrometric technique. Results show that in the visible region of solar spectrum, all the natural dye samples exhibit poor absorbance, except the sample of beetroot and strawberry. While $\mathrm{Ru}$ complex based synthetic dyes, exhibiting strong absorbance over the wide range in the visible spectrum. $\mathrm{Ru}$ based dye is characterized by large absorption coefficient in the visible part of solar spectrum as well as possess strong stability, efficient electron injection and suitable adsorption properties. The spectrum of the some of the natural dye has shown similar characteristics as Ru dye but at different absorbance range.

\subsection{Current Voltage (I-V) Characterization}

Photovoltaic performance of the DSSCs is determined using current voltage (I-V) curves. Current voltage characterization of the cell using synthetic and natural dyes is performed under one sun condition with AM 1.5 and maximum input power $100 \mathrm{~mW} / \mathrm{cm}^{2}$ as shown in the figure 4 . 


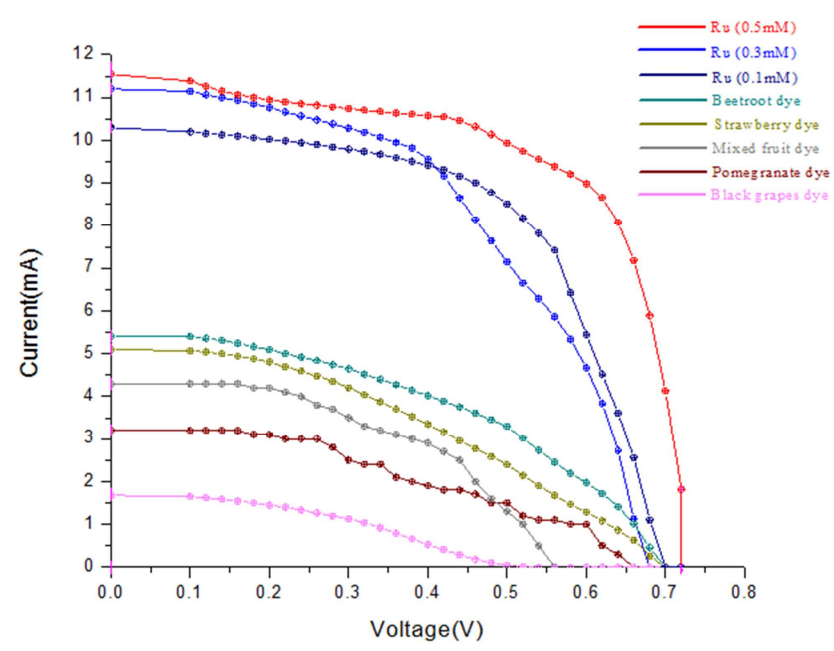

Photo-electro chemical properties of synthetic and natural dyes such as fill factor (FF) and efficiency have been calculated and the calculated record efficiencies of solar cells with Ruthenium N719 based synthetic and fruits extract based natural dyes are shown in table 1.

Photo-electro chemical properties of synthetic and natural dyes such as fill factor (FF) and efficiency

(1) Fill factor $=\frac{I m p \times V m p}{I s c \times V o c}$

(2) $\mathrm{Pmax}=I s c \times$ Voc $\times F F$

(3) Efficiency $\%(\eta \%)=\frac{P \max }{\operatorname{Pin}}=\frac{I s c \times \operatorname{Voc} \times F F}{\operatorname{Pin}}$

Figure 4. Current voltage response of cell with ruthenium based synthetic and fruits based natural dyes.

Table 1. Record efficiencies of Ruthenium N719 based synthetic and natural dyes based solar cells.

\begin{tabular}{|c|c|c|c|c|c|c|}
\hline Sample & Voc Volts & Isc $\mathbf{m A} / \mathrm{cm}^{2}$ & Vmp Volts & $\operatorname{Imp} \mathbf{m A} / \mathrm{cm}^{2}$ & Fill factor & $\operatorname{Efficiency}(\eta) \%$ \\
\hline $\mathrm{Ru}(0.5 \mathrm{mM}) \%$ & 0.72 & 11.5 & 0.54 & 9.4 & 0.63 & 5 \\
\hline $\mathrm{Ru}(0.3 \mathrm{mM}) \%$ & 0.69 & 11.1 & 0.59 & 8.13 & 0.60 & 4 \\
\hline $\mathrm{Ru}(0.1 \mathrm{mM}) \%$ & 0.67 & 10.2 & 0.47 & 7.54 & 0.40 & 3 \\
\hline Beetroot \% & 0.69 & 5.4 & 0.43 & 3.7 & 0.45 & 1.5 \\
\hline Strawberry & 0.69 & 5.09 & 0.42 & 3.1 & 0.43 & 1.3 \\
\hline Mixed dye & 0.56 & 4.29 & 0.37 & 2.9 & 0.41 & 1 \\
\hline Pomegranate & 0.66 & 3.17 & 0.34 & 2.3 & 0.37 & 0.7 \\
\hline Black grapes & 0.50 & 1.74 & 0.26 & 1.16 & 0.25 & 0.3 \\
\hline
\end{tabular}

The results are significant in case of synthetic dye and dyes based on fruit extract of beetroot and strawberry.

\section{Conclusion}

Results obtained from UV-Vis and I-V characterization of synthetic and low cost natural dyes based DSSCs show a comparison as well as great possibility of using DSSCs with natural dyes in a suitable manner. Absorption spectra of beetroot and strawberry, show peaks at $416 \mathrm{~nm}$ and $500 \mathrm{~nm}$ which are lying in visible range of solar spectrum. I-V characterization is performed under one sun condition and maximum efficiency of 5\% and $1.5 \%$ are obtained for the DSSCs based on synthetic and natural dyes respectively. By improving experimental conditions, an efficient and low cost natural dye based DSSC can be designed.

\section{Acknowledgement}

Authors are greatly thankful to, K.N. Chaturvedi Govt. Holkar Science College, Indore for providing the laboratory facilities. The authors are also thankful to V. Ganeshan, Mukul Gupta, Vinay Deshpandey and Shilpa Tripathi UGCDAE- Consortium for Scientific Research for their support in characterization of the samples and useful discussions.

\section{References}

[1] Gratzel, M (2005) Solar energy conversion by dye-sensitized photovoltaic cells. Inorg Chem 44: 6841-685.

[2] O'regan, B, Gratzel, M (1991) A low-cost, high-efficiency solar cell based on dye sensitized colloidal $\mathrm{TiO}_{2}$ films. Nature 353: 737-740.

[3] Greijer, H, Karlson, L, Lindquist, SE, Hagfeldt, A (2001) Environmental aspects of electricity generation from a nanocrystalline dye sensitized solar cell system. Renew Energy 23: 27-39.

[4] Dubois, DL (2009) Development of molecular electro catalysts for $\mathrm{CO}_{2}$ reduction and production/oxidation. AccChem Res 42: 1974-1982.

[5] Morris, AJ, Meyer, GJ, Fujita, E (2009) Molecular approaches to the photo catalytic reduction of carbon dioxide for solar fuels. AccChem Res 42: 1983-1994.

[6] Chiba, Y, Islam, A, Watanab, Y, Komiya, R, Koide, N, Han, L (2006) Dye-sensitized solar cells with conversion efficiency of 11.1\%. Jpn J ApplPhys 45: 1638-1640.

[7] Gratzel, M (2007) Photovoltaic and photo electrochemical conversion of solar energy. Phil Trans R Soc A 365: 9931005 . 
[8] Smestad, GP, Gratzel, M (1998) Demonstrating electron transfer and nanotechnology: a natural dye-sensitized nanocrystalline energy converter. J ChemEduc 75: 752-756.

[9] Patrocinio, AOT, Iha, NYM (2010) Toward sustainability, solar cells sensitized by natural extracts. Quim Nova 33: 574 578 .

[10] Davies, KM (2004) Plant Pigments and Their Manipulation. Blackwell Publishing Ltd, Palmerston North.

[11] Zhang XM, Chen YL, Liu RS, Tsai DP (2013) Plasmonic photo catalysis. Rep ProgPhys 76:046401.

[12] Zheng ZK, Huang BB, Qin XY, Zhang XY, Dai Y et al (2011) Facile in situ synthesis of visible light plasmonic photo catalysts $\mathrm{M} @ \mathrm{TiO}_{2}(\mathrm{M}=\mathrm{Au}, \mathrm{Pt}, \mathrm{Ag})$ and evaluation of their photo catalytic oxidation of benzene to phenol. J Mater Chem21: 9079-9087.

[13] Yang D, Sun YY, Tong ZW, Tian Y, Li YB et al (2015) Synthesis of $\mathrm{Ag} / \mathrm{TiO}_{2}$ nano tube hetero junction with improved visible light photo catalytic performance inspired by bio adhesion. J PhysChem C 119: 5827-5835.

[14] Wang XT, Liow C, Qi DP, Zhu BW, Leow WR et al (2014) Programmable photo electrochemical hydrogen evolution based on multisegmentedCdSAunanorod arrays. Adv Mater 26: $3506-3512$.

[15] Solarska R, Bienkowski K, Zoladek S, Majcher A, Stefaniuk $\mathrm{T}$ et al (2014) Enhanced water splitting at thin film tungsten trioxide photo anodes bearing plasmonic goldpolyoxometalate particles. Angew Chem 53: 14196-4200.

[16] Sellappan R, Nielsen MG, GonzálezPosada F, Vesborg PCK, Chorkendorff I et al (2013) Effects of plasmon excitation on photo catalytic activity of $\mathrm{Ag} / \mathrm{TiO}_{2}$ and $\mathrm{Au} / \mathrm{TiO}_{2}$ nanocomposites. J Catal 307: 214-221.

[17] Christopher P, Ingram DB, Linic S. Enhancing photochemical activity of semiconductor nanoparticles with optically active $\mathrm{Ag}$ nanostructures (2010) photochemistry mediated by Ag surface plasmons. J PhysChem C 114: 9173-9177.

[18] Zhang L, Blom DA, Wang $\mathrm{H}$ (2011) $\mathrm{AuCu}_{2} \mathrm{O}$ core shell nanoparticles: a hybrid metal semiconductor hetero nanostructure with geometrically tunable optical properties. Chem Mater 23: 4587-4598.

[19] Yu KF, Tian Y, TatsumaT(2006) Size effects of gold nano particles on Plasmon induced photocurrents of gold $\mathrm{TiO}_{2}$ nano composites. PhysChemChemPhys 8: 5417-5420.

[20] Torimoto T, Horibe H, Kameyama T, Okazaki K, Ikeda S et al (2011) Plasmonenhancedphotocatalytic activity of cadmium sulfide nanoparticle immobilized on silica coated gold particles. J PhysChemLett 2: 2057-2062.

[21] Thomann I, Pinaud BA, Chen ZB, Clemens BM, Jaramillo TF et al (2011) Plasmon enhanced solartofuel energy conversion. Nano Lett 11: 3440-3446.
[22] Shi XW, Ji YL, Hou S, Liu WQ, Zhang H et al (2015) Plasmon enhancement effect in Au gold nanorods@ $\mathrm{Cu}_{2} \mathrm{O}$ coreshell nanostructures and their use in probing defect states. Langmuir 31: 1537-1546.

[23] Seh ZW, Liu SH, Low M, Zhang SY, Liu ZL et al (2012) Janus $\mathrm{AuTiO}_{2}$ photo catalysts with strong localization of plasmonic near fields for efficient visible light hydrogen generation. Adv Mater 24: 2310-2314.

[24] Ren ST, Wang BY, Zhang H, Ding P, Wang Q (2015) Sandwiched $\mathrm{ZnO} @ \mathrm{Au} @ \mathrm{Cu}_{2} \mathrm{O}$ nanorod films as efficient visible light driven plasmonic photo catalysts. ACS Appl Mater Interfaces 7: 4066-4074.

[25] Ma X, Zhao K, Tang HJ, Chen Y, Lu CG et al (2014) New insight into the role of gold nanoparticles in $\mathrm{Au} @ \mathrm{CdS}$ core shell nanostructures for hydrogen evolution. Small 10: 4664 4670 .

[26] Mubeen S, Lee J, Singh N, Krämer S, Stucky GD et al (2013) An autonomous photosynthetic device in which all charge carriers derive from surface plasmons. Nat Nano 8: 247-251.

[27] Long R, Prezhdo OV (2014) Instantaneous generation of charge separated state on $\mathrm{TiO}_{2}$ surface sensitized with plasmonic nanoparticles. J Am ChemSoc 136: 4343-4354.

[28] Liu LQ, Ouyang SX, Ye JH (2013) Goldnanorodphotosensitized titanium dioxide with widerange visible light harvesting based on localized surface plasmon resonance. AngewChemInt Ed 52: 6689-6693.

[29] Kelly KL, Coronado E, Zhao LL, Schatz GC (2002) The optical properties of metal nanoparticles: the influence of size, shape, and dielectric environment. J PhysChem B 107: 668677.

[30] Gratzel, M (2003) Dye-sensitized solar cells. J PhotochemPhotobiol C Photochem Rev 4: 145-153.

[31] Chang, H, Wu, HM, Chen, TL, Huang, KD, Jwo, CS, Lo, YJ (2010) Dye-sensitized solar cell using natural dyes extracted from spinach and ipomoea. J Alloys Compd 495: 606-610.

[32] Gratzel, M, Hagfeldt, A (2000) Molecular photovoltaics. AccChem Res 33: 269-277.

[33] Ito, S, Saitou, T, Imahori, H, Uehara, H, Hasegawa, N: Fabrication of dye sensitized solar cells using natural dye for food pigment: monascus yellow. Energy Environ Sci 3, 905909 (2010).

[34] Ito, S, Murakami, TN, Comte, P, Liska, P, Gratzel, C, Nazeeruddin, MK, Gratzel, M (2008) Fabrication of thin film dye sensitized solar cells with solar to electric power conversion efficiency over 10\%. Thin Solid Films 516: 46134619 . 